\title{
The Evolution and Diversification of Blockchain Technology
}

\author{
Lingfei $\mathrm{Zhu}^{1, *}$ \\ ${ }^{1}$ Hangzhou Entel Foreign Language School, Hangzhou, China 311200
${ }^{*}$ Corresponding author. Email:2993176461@ qq.com
}

\begin{abstract}
The term around the blockchain technology is publicly confusing at present. At present, all terms related to blockchain technology make the public confused. However, the blockchain technology is the perfect example of using public shared information to enhance data security. It is essentially distributed database of records or public ledger of all transactions and digital footprints that have been executed and shared among all the parties. Each transaction in the public ledger is verified by a majority of the participants in the system, and once entered, the information can never be easily erased. This decentralized the peer-to-peer management system is being used in both financial and non-financial sector.

In this article, the author exams the application difficulties of the rapidly shifting technology, as well as to understand, govern and potentially apply this technology into real world businesses' operation, and offer suggestions such as additional regulation layers added by the government to ensure the integrity, as well as for how to appropriately implement blockchain technology throughout the society. The author draws out the conclusion of combining regulators' administration and the self-adjustment of the business industry to efficiently exploit the edges of blockchain technology.
\end{abstract}

Keywords : Blockchain, data security, decentralized system, cryptocurrency, smart contract, government utilization

\section{INTRODUCTION}

Blockchain technology itself has always been a controversial technique since it helps to enable an enormous and fast-growing global market of anonymous data transactions without any government control. In this article, the author will focus on a less discussed dilemma: regulators, commentators, and industry giants face a majority of challenges in approaching blockchain technology, especially in the world of finance, government cooperation and different social systems. The dilemmas include finding the right balance of the situation when such technology is available immediately for different parties. On top of that, the transactions need to be protected and to have guidance on how to appropriately structure and plan their businesses, but not so early that regulation inappropriately prohibit innovation on fin-tech as well as commercial banking, which bring the possibility and prosperity of new jobs or industries. Hence, the author will explore solutions and insights on how the regulators could rightfully promote the development of blockchain technology under rational supervision, and to put it into best use for the integration and progress of the society simultaneously.

\section{PROBLEMS ARISING AND REGULATORY INVESTIGATIONS THROUGHOUT}

\subsection{Growth and adoption of Blockchain}

Unsurprisingly, since the blockchain technology is still in the early growth phase of development, the core value is that the blockchain builds a system of creating a distributed consensus in the digital online world. This decentralized system allows parties in the blockchain to receive the signal for certain that a digital footprint happened by creating an irreversible record in a public ledger. This system opens the door for developing a democratic, scalable and decentralized digital economy from a centralized body. There are versatile applications 
as well as development in this disruptive technology and revolution in this space has just begun. Consequently, there will be a lack of general understanding and standards of how the public is accepting this method, making transactions in their respective business activities and daily trading[1]. In addition, the decentralization system which allows peer-to-peer transfer of value without the permission from a central intermediary highlighted by blockchain technology makes every party a bookkeeper, and the risk of money laundering and theft of information also increase the tension of proper authorities to investigate illegal financial activities more frequently. All of the developing application of blockchain technology is showing urgent need for government correction, as it will become a long term social and business trend of transferring and managing data. Even for the government itself, to use it in the public sector of conducting and providing social services such as welfare payments.

Table 1. Potential Issues

\begin{tabular}{|c|c|}
\hline Potential risk & Problems need for monitoring \\
\hline Strategic risk & $\begin{array}{l}\text { Businesses strategies can be affected by different parties } \\
\text { participating in the blockchain }\end{array}$ \\
\hline Operational risk & $\begin{array}{l}\text { Policymakers will need to update existing procedures to reflect } \\
\text { new process such as scalability }\end{array}$ \\
\hline Security risk & Blockchain technology does not provide account security \\
\hline Regulatory risk & $\begin{array}{l}\text { Uncertainty around the globe with different government } \\
\text { requirement related to blockchain applications especially with } \\
\text { cross-border transactions }\end{array}$ \\
\hline Continuity risk & $\begin{array}{l}\text { There may be technical, hardware failures and external attacks } \\
\text { which require a shorter response and recovery time }\end{array}$ \\
\hline Reputational risk & $\begin{array}{l}\text { Fail to evolve seamlessly with legacy system could lead to poor } \\
\text { customer experience[2] }\end{array}$ \\
\hline Supply chain risk & $\begin{array}{l}\text { Businesses have high dependence on third-party risk since } \\
\text { multiple technology used in the blockchain will be outsourced } \\
\text { from external providers }\end{array}$ \\
\hline
\end{tabular}

Table 1 shows the various risks which come along with its potential problems. It is obvious that the blockchain technology, with its high level of transaction security, also has its drawbacks. Take the first step of blockchain technology as an example, bitcoin, the first born of this technology, it was pointed out by a person named Satoshi Nakamoto at the end of 2008. A brand new system of peer-to-peer electronic cash has brought the discussion about cryptographers, a system with its unique features such as reduced credit cost in small casual transactions, and transaction fees certainly hit the world with a completely new method of financing. Since then, the Bitcoin system had never stopped, and the amount of users have been increasing in the whole world, the industry calls this as the era of blockchain technology 1.0, the centralized body also tasted its first challenge at that time. Yet, with its potential risks the author mentioned earlier,it is still difficult to know if governments and Bitcoin could have a productive future together. To understand this, it's important to go back in time and explore the origins of Bitcoin's revolutionary technology.

Table 2. The overview of Bitcoin

\begin{tabular}{|l|l|l|}
\hline \multicolumn{1}{|c|}{ Characterisrics } & \multicolumn{1}{|c|}{ Bitcoins } & \multicolumn{1}{|c|}{$\begin{array}{c}\text { Legally issued monetary } \\
\text { currency }\end{array}$} \\
\hline Issuer & $\begin{array}{l}\text { Issued by the system } \\
\text { automatically }\end{array}$ & $\begin{array}{l}\text { Central bank of the economy } \\
\text { based on the situation variable }\end{array}$ \\
\hline Manager & $\begin{array}{l}\text { Managed by a p2p network } \\
\text { and every participants inside } \\
\text { the network }\end{array}$ & $\begin{array}{l}\text { The government of the } \\
\text { economy }\end{array}$ \\
\hline Issuance capacity & Fixed (21 million BTC) & Adjusted by the central body \\
\hline Grounds for value & Trust in the p2p system & Trust in the government \\
\hline
\end{tabular}




\begin{tabular}{|l|l|l|}
\hline Time efficiency & $\begin{array}{l}\text { Create a block every ten } \\
\text { minutes }\end{array}$ & $\begin{array}{l}\text { Real time in the case of direct } \\
\text { receipt, yet It may take time } \\
\text { when transferring a large } \\
\text { amount of money to a } \\
\text { distance, or with strict audit } \\
\text { processes }\end{array}$ \\
\hline Transfer fees & $\begin{array}{l}\text { Relatively small amount and } \\
\text { buried by the senders }\end{array}$ & $\begin{array}{l}\text { Large amount and buried by } \\
\text { both parties in the two-way } \\
\text { transaction }\end{array}$ \\
\hline $\begin{array}{l}\text { Disclosure of transaction } \\
\text { records }\end{array}$ & Disclosed & \begin{tabular}{l} 
Undisclosed \\
\hline
\end{tabular}
\end{tabular}

Table 2 shows the comparison between bitcoins and legal currency, The fact is that the government is showing concerns about this technology, such as the loss of control due to decentralization. For example, the Chinese central government have the power to control traditional currencies: RMB.They can track the movement of money in the economy, which can earn profits and collect tax accordingly. On top of that, it can also give the government the edge of tracking criminal or fraudulent activities performed with the fiat currencies easily. The control of the currency gives the government power to influence the economy, create a monetary policy, foster financial transactions. With the creation of bitcoin, the Chinese government is worrying about losing control over the money transaction system due to decentralization. As bitcoin's underlying technology does not allow any central authority for any transaction, the related authorities cannot regulate the monetary policy and loses its power as discussed before, the risk of money laundering. Thus, the Chinese government is now pushing to publish its own electronic currency.

\subsection{Governments' action as Blockchain became more versatile}

The same dilemma also occurs when blockchain 2.0 and 3.0 came out, as we know generally as smart contracts, developed from business websites to almost applicable for every transaction activity, the technology also emerged to the surface in the business world. That lack of a framework was also mentioned at the Organisation for Economic Co-operation and Development Global Blockchain Policy Forum held at the end of 2019, the forum specifically pointed out that without such an appropriate framework, the economic implications of central body usage of so-called stablecoins, would be unpredictable and wide ranging[3]. The lessons learned from government adoption of blockchain range from addressing the security implications of ledger transparency through cryptography to planning for the increased costs of implementing blockchain relative to more mature technology.
To get familiar, to start, to adapt, to even apply in the central body's own use for such a technology, the central power must work to educate themselves about blockchain technology, so that their understanding of the technology can be less affected by vocabulary problems. If regulators are well educated, they will be able to apply and educate the public in a more sensitive way, they will also be alert to over-defined or under-defined terminology and subtle but consequential distinctions between variants of the technology on some oocasion, and able to respond to these nuances in their analyses. Governments worldwide have started to develop policies or government strategies for the adoption of solutions, even the World Bank is pushing the pace of letting respective governments to publish its own digital currencies, the experience that they have gained with cryptocurrencies has helped them in how to use blockchain technology to reduce transaction costs. They may make clear that it is more efficient to execute cross-border trade transactions through blockchain by cryptocurrency. The realization of such transactions, however, requires complex integration work and a conducive regulatory environment, strengthening the global partnership building ecosystem[4]. Governments that utilize blockchain technology should partner with private firms such as commercial banks and other financial institutions to both encourage innovation and develop a flexible legal framework. A perfect example is the UAE's support of blockchain, in which they created a regulatory sandbox for technology companies to test blockchain solutions, both for FinTech and for streamlining data interoperability across government services. In the United States, the Accelerator program is similar in its support of public-private collaboration and has discussed how to use blockchain for identity management, an accelerator for public-private partnerships, tracking human trafficking, Visas, and shipping fraud. Public-private collaborations should focus on developing blockchain interoperability and standardization, as applied to a carefully selected set of inefficient bureaucratic use cases.

As for security problems, Consensus protocols will be the core solution on this topic, it is suggested that before adopting a blockchain solution, the underlying mechanism and the system implementation should be 
fully reviewed and discusssed. Even though most peer-reviewed works have been carefully reviewed by industry experts[4], errors in some solutions are still found later. Therefore, it is important to evaluate whether the implementation matches the design of the blockchain. Some efforts have been made for e-government applications such as multiple monitoring applications in conducting blockchain technology. What's more, when it comes to transaction fee, for digital platforms, blockchain can reduce the cost to star-ups for finding new marketplaces, as well as audit the authenticity of transactions. However, their decentralized nature can introduce new inefficiencies and data governance issues. Blockchains' main advantages in guaranteeing data integrity through inversion may come on top, relative to having the same guarantee in a centralized application. Transaction costs have been found to be higher for permissionless blockchains when compared to centralized solutions, and blockchain applications can cost significantly more to operate than a cloud-based centralized equivalent, even after controlling for cloud service utilization fees which could be reduced even more after the government subsidies. In a word, it is clear to see that the government should act as a co-responding correcting party as issues arises from applying this technology into real business use.

Last but not least, for the problems of data quality and suppliers' risk, Blockchain does not protect against data from untrustworthy or unknown sources, such as authorized but potentially tainted parties. It cannot prevent well-formatted but incorrect or inaccurate data from being sent and stored in the $\mathrm{p} 2 \mathrm{p}$ network. As a result, blockchain may be used as an illegal content distribution channel which will definitely cause a market failure. The system may also consist of data with low quality or high inaccuracy. Such data quality issues might be harmful in applications where transparency of the data is desirable, especially in government applications, for example, the system of welfare payments as pension or unemployment, such problem will cause a distortion. Although blockchain can be used as an auditing system for authenticating these data, the data are already distributed and cannot be retrieved from all parties with certainty. A decentralized system that allows any two parties in the blockchain to anonymously exchange assets may provide a safe harbor for those wishing to perform tacit activities without fear of reprisal. As a result, existing solutions usually involve additional layers to detect or ensure data quality, this is important since almost everything can be done through government application or mini applications, use China as an example. It is not clear whether such a layer added by the government will provide the desirable analysis and become generic enough to ensure data quality.

\section{KEY FOR CORRECTION}

Blockchains have evolved beyond cryptocurrencies as the 1.0 era, to general purpose and can be used across an array of applications, particularly those that need high service availability and data integrity. If their level of adoption increases, then blockchain-based solutions may reintroduce a trusted broker: the data center, whether in the cloud or on premise, the author believes this could be the key to the regulators for correcting the market, A cloud-based blockchain system makes the cloud developer into a new type of trusted agent. If instead nodes(as all nodes on a blockchain are interactively connected and they exchange the latest blockchain data over time)are on premise but are used by the public, then whatever entity is hosting them becomes the trusted agent[7], and the system becomes vulnerable to any failures that may render the entire system unreliable. Therefore, replacing a corruptable human or bureaucracy with a blockchain may shift risk rather than eliminate it.

\section{CONCLUSION}

In conclusion, the challenges and prosperity for blockchains, such as being fully privacy conserving, ensuring compliance at any time nodes needed, and being scalable,are not yet to be fully solved, and more work is needed to address them for the central body to correctly apply this technology into a country-based level, in addition, the methods mentioned in this article are highly depends on the awareness of all business parties, and the implementation requires a high level of commitment from all the central bodies, so it is safe to say that in the long term, a more comprehensive approach is needed.Yet despite these challenges, blockchains can make applications better and will begin to be the solution for use case - specific distributed systems problems, such as high density data transfer in banking and accounting. Most blockchain applications were found in the financial area at first, just as many good and proven technologies have been. Blockchains are now being used in other spaces, such as government. They may be the best technology to deploy when a need to distribute data through a system that needs to guarantee data integrity and service availability exists, the ability to make it happen is limited, we should hold an open-minded thought and keep push the inter-world cooperation to adapt and coexist with blockchain technology.

\section{ACKNOWLEDGMENTS}

Many people have offered me supportive and valuable suggestions with my essay. Firstly, I would like to thank my supervisor, Professor Ming Han, without her consistent and illuminating instruction, it would be impossible for me to complete my essay. 
Also, I am extremely grateful to my tutors, Professor Tuffy Guo, for her treasured support which was really insightful,

Some special thanks go to my friend, for his assistance as well as enlightening comments throughout the preparation of the essay had been helpful.

Finally, for all the people who have supported me and encouraged me to complete the work directly or indirectly, I would like to extend my greatest gratitude .

\section{REFERENCES}

[1] Benjamin Ross. 2018. US health and human services looks to blockchain to manage unstructured data. Clinical Research News. Retrieved October 21, 2020 from https://www.clinicalresearchnewsonline.com/2018/ 11/29/us-health-and-human-services-looks-to-bloc kchain-to-manage-unstructured-data.

[2] Qiuyun Shang and Allison Price. 2019. A blockchain-based land titling project in the Republic of Georgia: Rebuilding public trust and lessons for future pilot projects. Innovations: Technology, Governance, Globalization 12, 3--4 (2019), 72-78.

[3] João Sousa, Eduardo Alchieri, and Alysson Bessani. 2014. State machine replication for the masses with BFT-SMaRT. In Proceedings of the 2014 44th Annual IEEE/IFIP International Conference on Dependable Systems and Networks (DSN'14). 355-362.

[4] Clare Sullivan and Eric Burger. 2017. E-residency and blockchain. Computer Law \& Security Review 33, 4 (2017), 470-481.

[5] GitHub. n.d. Tendermint Core. Retrieved October 21, 2020 from https://github.com/tendermint/tendermint.

[6] Vireshwar Tomar. 2020. Indian Government Policy Think Tank Releases National Blockchain Strategy. Retrieved October 21, 2020 from https://www.sogou.com/link?url=hedJjaC291NkO xbQNuXMB_nRsnvCuFsHmUKUW9aQsdinz6rcJ cF8y0N9k-jvbtNZrOikAlNPoSaqnToFhvMpKRT GFj4YBy-jPjYADeHxrOY1r_fE_MTIUjIrDt87lpr iH26743_pKm8ut5pUc3zy0dg.

[7] Rachel Davidson Raycraft , Ashley Lannquist,15 Jun 2020.How governments can leverage policy and blockchain technology to stunt public corruption from https://www.weforum.org/agenda/2020/06/govern ments-leverage-blockchain-public-procurement-co rruption/ 